ARTICLE

Received 19 Apr 2013 | Accepted 16 Jul 2013 | Published 22 Aug 2013 DOl: 10.1038/ncomms3323

\title{
Reductive assembly of cyclobutadienyl and diphosphacyclobutadienyl rings at uranium
}

Dipti Patel ${ }^{1}$, Jonathan McMaster ${ }^{1}$, William Lewis ${ }^{1}$, Alexander J. Blake ${ }^{1} \&$ Stephen T. Liddle ${ }^{1}$

Despite the abundance of f-block-cyclopentadienyl, arene, cycloheptatrienyl and cyclooctatetraenide complexes, cyclobutadienyl derivatives are unknown in spite of their prevalence in the d-block. Here we report that reductive $[2+2]$-cycloaddition reactions of diphenylacetylene and (2,2-dimethylpropylidyne)phosphine with uranium(V)-inverted sandwich $10 \pi$-toluene tetra-anion complexes results in the isolation of inverted sandwich cyclobutadienyl and diphosphacyclobutadienyl dianion uranium(IV) complexes. Computational analysis suggests that the bonding is predominantly electrostatic. Although the $\psi_{4}$ molecular orbital in the cyclobutadienyl and diphosphacyclobutadienyl ligands exhibits the correct symmetry for $\delta$-bonding to uranium, the dominant covalent contributions arise from $\pi$-bonding involving $\psi_{2}$ and $\psi_{3}$ orbital combinations. This contrasts with uranium complexes of larger arenes and cyclo-octatetraenide, where $\delta$-bonding dominates. This suggests that the angular requirements for uranium to bond to a small four-membered ring favours $\pi$-bonding, utilizing $5 \mathrm{f}$ - instead of $6 \mathrm{~d}$-orbitals, over $\delta$-bonding that is favoured with larger ligands, where $6 \mathrm{~d}$-orbitals can become involved in the bonding.

\footnotetext{
${ }^{1}$ School of Chemistry, University of Nottingham, University Park, Nottingham NG7 2RD, UK. Correspondence and requests for materials should be addressed to S.T.L. (email: stephen.liddle@nottingham.ac.uk).
} 
T he recognition that metals can engage in $\pi$ - and $\delta$-bonding to carbocyclic ligands in addition to classical $\sigma$-bonding interactions, as exemplified by the landmark discovery of the structure of ferrocene ${ }^{1,2}$, heralded a new age of organometallic chemistry $^{3}$. Since the inception of the field, $\pi$-ligand complexes of d-block metals with cyclo-octatetraenide, cycloheptatrienyl, arene, cyclopentadienyl and cyclobutadienyl have been investigated extensively ${ }^{4}$. These ligands, together with allyl and alkene ligands, constitute the important class of $\pi$-bound organometallic ligands that have proven instrumental in the development of d-orbital bonding theory. The strategy of using metals to construct and stabilize reactive $\pi$-systems has met with much success, for example, affording otherwise inaccessible organic groups, such as the square, rather than rectangular form of cyclobutadiene ${ }^{5}$. Furthermore, metal $\pi$-complexes find numerous applications in organic synthesis and catalysis, where complexation of a metal can increase or invert the reactivity of $\pi$-systems ${ }^{6-8}$.

In the f-block, lanthanide complexes of carbocyclic $\pi$-ligands constitute a mature aspect of organolanthanide chemistry ${ }^{-11}$. In part, this is because anionic $\pi$-ligands, such as cyclopentadienyl, bind strongly to metal centres whose bonding can be principally characterized as electrostatic. In addition, convenient synthetic methods, usually involving salt elimination, are also readily available for the straightforward installation of $\pi$-ligands, such as cyclopentadienyl and cyclo-octatetraenide, into the coordination sphere of lanthanides. For uranium, there has been intense interest in uranium $\pi$-ligand interactions because of the possibility of greater covalent metal-ligand bonding compared with the lanthanides and the implications for $\mathrm{f}$-orbital bonding theory and reactivity ${ }^{12-17}$. Nonetheless, with the notable exception of cyclopentadienyl derivatives, progress has generally been hampered by a lack of synthetic methods or suitable ligand transfer reagents. The first uranium- $\pi$-ligand complex employed cyclopentadienyl in the complex $\left[\mathrm{U}\left(\eta^{5}-\mathrm{C}_{5} \mathrm{H}_{5}\right)_{3} \mathrm{Cl}\right]$, which was reported in 1956 by Wilkinson ${ }^{18}$, and was subsequently authenticated structurally by Yen in 1965 (ref. 19). This was followed by the landmark complex uranocene $\left[\mathrm{U}\left(\eta^{8}-\mathrm{C}_{8} \mathrm{H}_{8}\right)_{2}\right]^{20}$, using the cyclo-octatetraenide dianion ligand, first reported by Streitwieser in 1968 and later characterized structurally by Raymond in 1969 (ref. 21). The cycloheptatrienyl anions $\left[(\mathrm{L})_{3} \mathrm{U}\left(\mu-\eta^{7}: \eta^{7}-\mathrm{C}_{7} \mathrm{H}_{7}\right) \mathrm{U}(\mathrm{L})_{3}\right]^{-}\left[L=\mathrm{BH}_{4}\right.$ or $\left.\mathrm{NEt}_{2}\right]$ and $\left[\mathrm{U}\left(\eta^{7}-\right.\right.$ $\left.\left.\mathrm{C}_{7} \mathrm{H}_{7}\right)_{2}\right]^{-}$were reported by Ephritikhine ${ }^{22,23}$ in 1994 and 1995, respectively, and these compounds still constitute the only examples of uranium-cycloheptatrienyl complexes in the literature. The first $\pi$-arene complex of uranium, $\left[\mathrm{U}\left(\eta^{6}\right.\right.$ $\left.\mathrm{C}_{6} \mathrm{H}_{6}\right)\left(\mathrm{AlCl}_{4}\right)_{3}$ ], was reported by Cesari et al. ${ }^{24}$ in 1971 , and more recently, diuranium arene inverted sandwich complexes have become prevalent ${ }^{25-36}$. However, and in contrast to the d-block, the notable exception that is absent from this series of carbocyclic $\pi$-ligands is that of cyclobutadienyl. Indeed, given the prominence of $\pi$-bound ligands in organo-f-block chemistry, it is significant and surprising to note that there are no reports of any f-block cyclobutadienyl complexes ( $4 \mathrm{f}$ or $5 \mathrm{f}$ ). Notably, although the coupling of alkynes in the presence of uranium is well known, this typically affords acyclic chains via insertion reactions $s^{37-40}$. Where the reductive oligomerization of alkynes is employed, uranium-coordinated butadienyls or vinyl complexes are formed exclusively ${ }^{41}$. This contrasts with d-block systems that readily and efficiently execute $[2+2]$-cycloadditions of alkynes to give cyclobutadienyl complexes ${ }^{42}$.

The contrasting dearth and prevalence of f-block and d-block cyclobutadienyls, respectively, suggest that orbital considerations may have an important role in overcoming the inherent strain in assembling a four-membered cyclobutadienyl ring, even when this may be offset by subsequent aromatic stabilization. However, electrostatic interactions dominate the bonding of uranium to ligand donors and, thus, steric factors may also remain important with respect to the assembly of a four-membered cyclobutadienyl ring bound to a metal centre. Herein, we show that high-valent uranium-arene complexes, supported by sterically rigid, trianionic tris $(N$-arylamidodimethylsilyl)methane ligands, are competent reagents for the reductive assembly of inverse sandwich uranium-cyclobutadienyl and uranium-diphosphabutadienyl complexes through formal $[2+2]$-cycloaddition reactions of alkyne or phospha-alkyne precursors, respectively. These complexes are the first f-block cyclobutadienyl derivatives and our studies provide insight into the chemical bonding of these systems.

\section{Results}

Synthesis. Recently, as part of our work exploring triamido uranium chemistry, we reported the uranium inverse sandwich toluene complexes $\left[\left\{\mathrm{U}\left(\mathrm{Ts}^{\mathrm{R}}\right)\right\}_{2}\left(\mu-\eta^{6}: \eta^{6}-\mathrm{C}_{6} \mathrm{H}_{5} \mathrm{Me}\right)\right] \quad(1, R=3,5-$ $\mathrm{Me}_{2} \mathrm{C}_{6} \mathrm{H}_{3}, \mathrm{Xy} ; \quad 2, \quad R=4-\mathrm{MeC}_{6} \mathrm{H}_{4}$, tol $)^{31,35}$. The structural, magnetic, spectroscopic and computational data of $\mathbf{1}$ and $\mathbf{2}$ are consistent with a new class of uranium-arene complex containing uranium $(\mathrm{V})$ ions and $10 \pi$-electron toluene tetra-anions. In these complexes it appears that achieving filled, closed shell $\psi_{4}$ and $\psi_{5}$ molecular orbitals of the $10 \pi$-arene, together with $\delta$-bonding to the uranium centres, prevents oxidation of the toluene tetra-anion by uranium(V). Nevertheless, these complexes are strongly reducing, as demonstrated by the reaction of $\mathbf{1}$ with $\left[\left\{\mathrm{Co}(\mathrm{CO})_{3}\left(\mathrm{PPh}_{3}\right)\right\}_{2}\right]$ to afford, through reductive cleavage of the cobalt-dimer and uranium(V) $\rightarrow$ uranium(IV) reduction, a uranium(IV)-cobalt bond in $\left[\mathrm{U}\left(\mathrm{Ts}^{\mathrm{Xy}}\right) \mathrm{Co}(\mathrm{CO})_{3}\left(\mathrm{PPh}_{3}\right)\right]^{31}$. We thus identified these complexes as possible precursors to uranium-cyclobutadienyl complexes because of their reducing nature and the possibility of the variation of the $N$-aryl substituents, as the variation of ligand sterics is key to modulating f-block stability and reactivity.

Addition of four equivalents of diphenylacetylene to $\mathbf{1}$ in toluene afforded a rapid colour change from red to brown. The use of fewer equivalents of diphenylacetylene resulted in very slow reactions and intractable product mixtures. When the toluene solvent is removed and replaced with hexane, and the resulting solution is stored at room temperature for 43 days, brown crystals of the diuranium-cyclobutadienyl inverse sandwich complex, a product of a formal reductive [2+2]-cycloaddition reaction, $\left[\left\{\mathrm{U}\left(\mathrm{Ts}^{\mathrm{Xy}}\right)\right\}_{2}\left(\mu: \eta^{5} \eta^{5}-\mathrm{C}_{4} \mathrm{Ph}_{4}\right)\right]$ (3), are reproducibly isolated in $20 \%$ crystalline yield, Fig. 1. Interestingly, the ${ }^{1} \mathrm{H}$ NMR spectrum of 3 exhibits 6 resonances for the cyclobutadienyl phenyl protons in a 4:4:4:4:2:2 ratio (Supplementary Figure S1); this can be accounted for by invoking an asymmetric coordination mode of the $\mathrm{C}_{4} \mathrm{Ph}_{4}^{2-}$ group in solution which suggests the solid state structure (vide infra) is maintained in solution. Inspection of the crude toluene reaction mixture by ${ }^{1} \mathrm{H}$ NMR spectroscopy revealed the presence of an intermediate species (Supplementary Figure S2). Despite numerous attempts, the intermediate could not be isolated, and the ${ }^{1} \mathrm{H}$ NMR spectrum of the crude reaction mixture cannot be assigned due to its complexity, but we suggest it is a coupled, but not ring-closed, butadienedianion similar to the bimetallic uranium-vinyl complexes recently reported by Meyer ${ }^{41}$. The crude mixture is formed quickly in toluene but shows only slow conversion to $\mathbf{3}$, and it would seem that use of the less polar solvent hexane enforces precipitation of $\mathbf{3}$, thus driving the equilibrium. The long recrystallization time may be connected with the energetic barrier associated with cyclization that must be overcome to afford 3 and may also reflect the high solubility of 3. Notably, when the mother liquor is decanted from crystals of $\mathbf{3}$ and stored, 


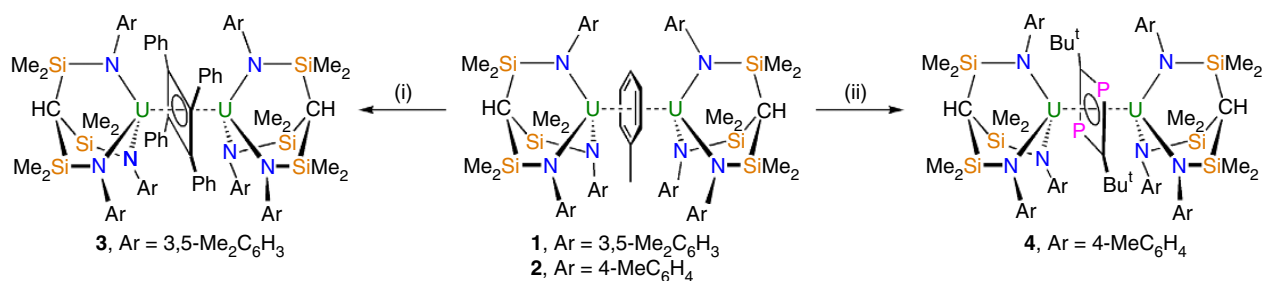

Figure 1 | Synthesis of 3 and 4. Reagents and conditions: (i) Toluene, 4 PhCCPh, -toluene, recrystallized from hexane, 43 days, $20 \%$; (ii) toluene, 2 $\mathrm{Bu}^{\mathrm{t}} \mathrm{C} \equiv \mathrm{P} \mathrm{O}\left(\mathrm{SiMe}_{3}\right)_{2}$, recrystallized from toluene, yield $69 \%$. Crude ${ }^{1} \mathrm{H}$ NMR spectra obtained during the preparation and isolation of $\mathbf{3}$ show another species that could not be isolated, which is presumed to be a coupled butadienedianion which ring closes to give $\mathbf{3}$. For the synthesis of $\mathbf{1}$ and $\mathbf{2}$ (refs 31,35 ).

more crystalline 3 is eventually deposited, which supports the notion that a vinyl intermediate that slowly converts to 3 is present. When 1 is treated with bis(trimethylsilyl)acetylene, no reaction is observed; although electronic considerations cannot be ignored, we suggest that the absence of reactivity with bis(trimethylsilyl)acetylene may be steric in origin. We also attempted the reaction between diphenylacetylene and $\mathbf{2}$ to give the para-tolyl analogue of $\mathbf{3}$, but this yields an intractable mixture of products that have resisted all attempts at identification. This latter observation suggests that the combination of the tetraphenyl-substituted cyclobutadienyl group with a xylylfunctionalized $\left[\mathrm{U}\left(\mathrm{Ts}^{\mathrm{X}} \mathrm{y}\right)\right]^{+}$group represents the optimum steric combination with the tris( $N$-arylamidodimethylsilyl)methane ligand set.

As the reaction that afforded 3 yields the first example of an f-block cyclobutadienyl complex, but is relatively slow, we targeted a more polar triple bond in an effort to effect a more rapid $[2+2]$-cycloaddition reaction. We identified the phosphaalkyne $\mathrm{Bu}^{\mathrm{t}} \mathrm{C} \equiv \mathrm{P}$ as a suitable reagent due to its $\delta-\mathrm{C} \equiv \mathrm{P}^{\delta+}$ polarization that should favour cycloaddition reactions and the isoelectronic relationship of $\mathrm{P}$ to a $\mathrm{CR}$ group. Reaction of excess $\mathrm{Bu}^{\mathrm{t}} \mathrm{C} \equiv \mathrm{P}$ with $\mathbf{1}$ does not result in the formation of $\left[\left\{\mathrm{U}\left(\mathrm{Ts} \mathrm{sy}^{\mathrm{X}}\right)\right\}_{2}\left(\mu: \eta^{4} \eta^{4}-\mathrm{C}_{2} \mathrm{P}_{2} \mathrm{Bu}_{2}^{\mathrm{t}}\right)\right]$; no reaction is observed and eventually 1 decomposes on extended storage in solution; and we attribute this lack of reactivity to steric blocking as for the attempted reaction of bis(trimethylsilyl)acetylene with $\mathbf{1}$ (vide supra). However, replacing $\mathbf{1}$ with the sterically less demanding $\mathbf{2}$ results in a clean reaction with two equivalents of $\mathrm{Bu}^{\mathrm{t}} \mathrm{C} \equiv \mathrm{P}$ to give the diphosphacyclobutadienyl complex $\left[\left\{\mathrm{U}\left(\mathrm{Ts}^{\mathrm{Tol}}\right)\right\}_{2}\left(\mu: \eta^{4} \eta^{4}-\right.\right.$ $\mathrm{C}_{2} \mathrm{P}_{2} \mathrm{Bu}_{2}^{\mathrm{t}}$ )] (4) as red crystals in $69 \%$ yield following workup and recrystallization from toluene, Fig. 1 . The ${ }^{1} \mathrm{H}$ NMR spectrum for $\mathbf{4}$ is suggestive of a relatively symmetric species in solution with only six resonances observed (Supplementary Figure S3), and the ${ }^{31} \mathrm{P}$ NMR spectrum exhibits a resonance at $\sim 535$ p.p.m. The total reaction time for the formation and isolation of $\mathbf{4}$ is $\mathrm{ca}$ $24 \mathrm{~h}$ compared with 43 days for 3 . In addition, no intermediates are observed during the formation of 4 , which is in-line with the anticipated enhanced reaction rates for the polar phospha-alkyne compared with the diphenylacetylene. It would also seem that modest reduction of the steric bulk of the $N$-aryl groups affords sufficient space to enable tert-butyl groups to fit into the pocket between the two $\left[\mathrm{U}\left(\mathrm{Ts}^{\mathrm{Tol}}\right)\right]^{+}$units, thus underscoring the importance of ligand-substituent modification for controlling the stability of the complex. Finally, the absence of any higher homologated phospha-alkyne products, for example, tri-tertbutyltriphosphabenzene, suggests that the size match of two $\left[\mathrm{U}\left(\mathrm{Ts}^{\mathrm{Tol}}\right)\right]^{+}$units and $\left(\mathrm{C}_{2} \mathrm{P}_{2} \mathrm{Bu}_{2}^{\mathrm{t}}\right)^{2-}$ is selective for diphosphacyclobutadienyl formation.

Structural characterizations. The solid state structures of $\mathbf{3}$ and $\mathbf{4}$ have been determined by X-ray crystallography (Supplementary

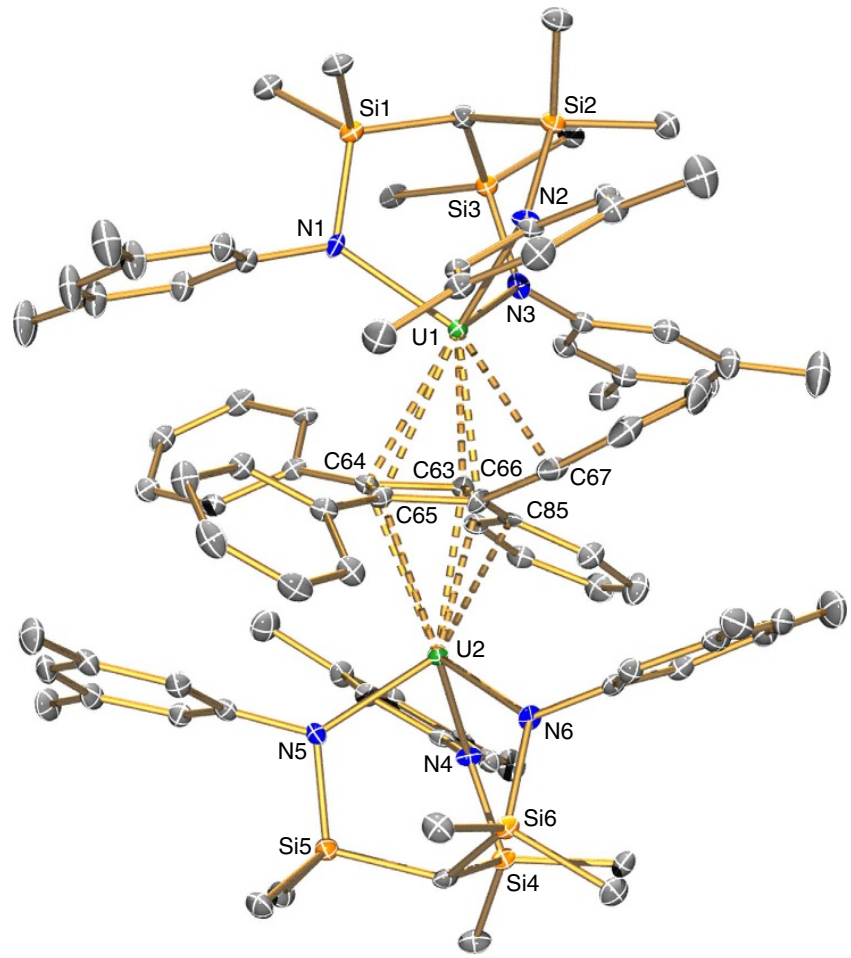

Figure 2 | Solid state structure of 3. Displacement ellipsoids are set to $40 \%$ probability. Lattice solvent molecules, minor disorder components and hydrogen atoms are omitted for clarity. Selected distances $(\AA)$ : U1-N1 2.263(4), U1-N2 2.261(4), U1-N3 2.261(4), U2-N4 2.247(4), U2-N5 2.265(4), U2-N6 2.245(4), U1-C63 2.655(5), U1-C64 2.871(5), U1-C65 2.861(5), U1-C66 2.660(5), U1 ‥C67 2.887(5), U2-C63 2.664(5), U2-C64 2.860(6), U2-C65 2.855(5), U2-C66 2.655(5) and U2 . .C85 2.842(5).

Tables S1-S3, and Supplementary Data 1 and 2) and are illustrated in Figs 2 and 3 with selected bond lengths and angles. The crystal structure of 3 reveals a dinuclear structure, where the bridging group is a tetraphenylcyclobutadienyl ligand. This is an unprecedented coordination mode for the $\mathrm{C}_{4}$-ring of this dianion that ordinarily binds in an $\eta^{4}$-manner to one metal only ${ }^{42}$. Close inspection reveals that two of the phenyl rings on one side of the four-membered ring exhibit close contacts, one to each uranium $(\mathrm{U} 1 \cdots \mathrm{C} 672.887(5), \mathrm{U} 2 \cdots \mathrm{C} 852.842(5) \AA)$, to give a $\mu: \eta^{5} \eta^{5}$ coordination mode overall. This enforces an asymmetric coordination of the four-membered ring that results in $\mathrm{U}-\mathrm{C}$ bond distances that span a relatively wide range of 2.655(5)2.871(5) A. Consequently, the U-C distances between the cyclobutadienyl ring and two uranium centres fall into two pairs with 
bond lengths of $c a 2.66$ and $2.86 \AA$, respectively, as a result of the asymmetric coordination of the cyclobutadienyl ring, and, as a consequence, each uranium ion resides essentially midway above and below the $\mathrm{C} 63-\mathrm{C} 66$ bond. The $\mathrm{U}-\mathrm{C}_{\text {ipso }}$ distances (U1 . . C67 and $\mathrm{U} 2 \cdots \mathrm{C} 85$ ) are comparable to the longer pair of $\mathrm{U}-\mathrm{C}_{\text {ring }}$ bonds in 3. Furthermore, although the two non-coordinated phenyl rings exhibit ispo-carbons that are in the plane of the cyclobutadienyl ring, the two 'coordinated' phenyl rings display $\mathrm{C}_{\text {ipso }}$ carbon centres that deviate $+0.61(\mathrm{C} 67)$ and $-0.64(\mathrm{C} 85) \AA$ above and below this plane. Taken together, these two features are suggestive of significant $\mathrm{U}-\mathrm{C}_{i p s o}$ interactions. The cyclobutadienyl $\mathrm{C}-\mathrm{C}$ distances are indistinguishable from one another and average $1.484 \AA$, which is fully consistent with a delocalized $6 \pi$-electron cyclobutadienyl system, as would be expected if the cyclobutadienyl ring carries a dianionic charge ${ }^{43}$. The U-N bond distances average $2.257 \AA$, which is unexceptional for uraniu$\mathrm{m}(\mathrm{IV})$-amide bond lengths ${ }^{44}$.

The solid state structure of $\mathbf{4}$ is similar to $\mathbf{3}$, but clearly shows the formation of a bridging diphosphacyclobutadienyl ligand that is reminiscent of the planar $\left[\mathrm{P}_{4}\right]^{2-}$ rings found in the complexes $\left[\mathrm{U}\left(\eta^{5}-\mathrm{C}_{5} \mathrm{Me}_{5}\right)\left\{\eta^{8}-\mathrm{C}_{8} \mathrm{H}_{6}\left(-1,4-\mathrm{SiPr}_{3}\right)_{2}\right\}\right]_{2}\left(\mu-\eta^{2}: \eta^{2}-\mathrm{P}_{4}\right)^{45}$ and $\left[\mathrm{U}\left\{\mathrm{N}(\mathrm{Ar}) \mathrm{Bu}^{\mathrm{t}}\right\}_{3}\right]_{2}\left(\mu-\eta^{4}: \eta^{4}-\mathrm{P}_{4}\right) \quad\left(\mathrm{Ar}=3,5-\mathrm{Me}_{2} \mathrm{C}_{6} \mathrm{H}_{3}\right)^{46}$. The coordination mode of the four-membered $\mathrm{P}_{2} \mathrm{C}_{2}$ ring to the uranium centres is more symmetrical than the $\mathrm{C}_{4}$-ring in 3, presumably as a result of replacement of $\pi$-electron-rich phenyl rings with tert-butyl substituents. The $\mathrm{P}-\mathrm{C}$ distances range from 1.794 (2) to $1.810(2) \AA$ and are indicative of a delocalized $\mathrm{P}_{2} \mathrm{C}_{2}$ ring carrying a 2- charge. The U-P and U-C distances span the ranges 2.9081(5)-3.0358(5) $\AA$ and 2.778(2)-2.981(2) $\AA$, respectively, and these values are in good agreement with $\mathrm{U}-\mathrm{P}$ and $\mathrm{U}-\mathrm{C}$ distances of ca 2.93 and $2.81 \AA$, typically observed in $\eta^{5}$-phospholide

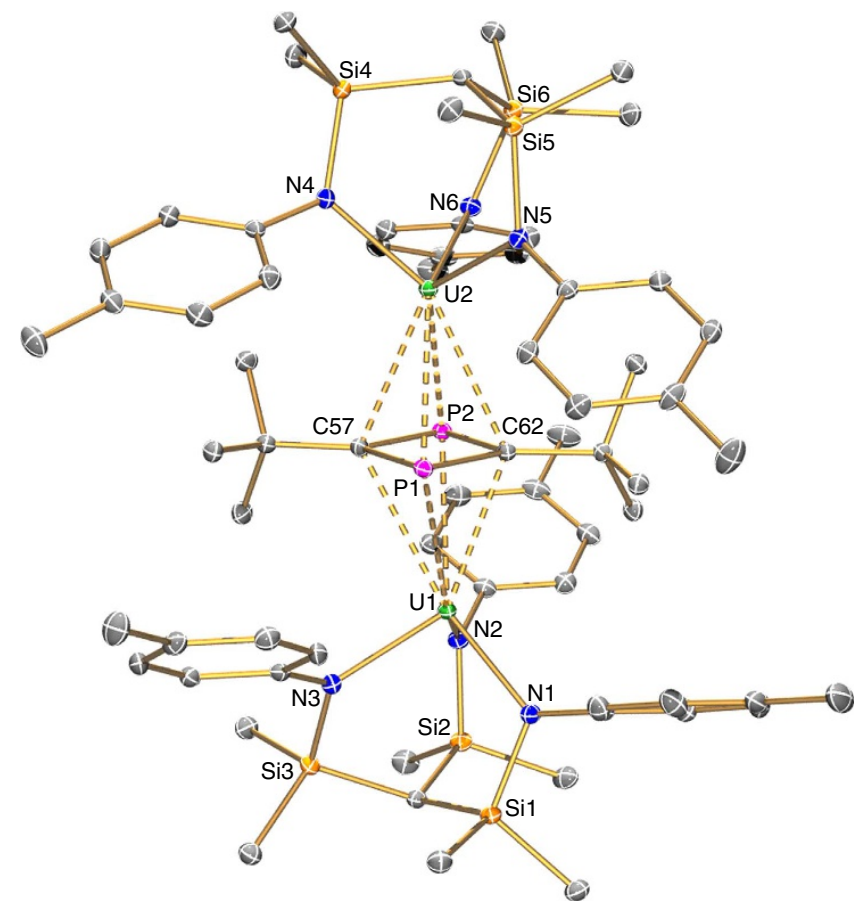

Figure 3 | Solid state structure of 4. Displacement ellipsoids set to $40 \%$ probability. Lattice solvent molecules, minor disorder components and hydrogen atoms are omitted for clarity. Selected distances $(\AA)$ : U1-N1 2.2235(18), U1-N2 2.2337(18), U1-N3 2.2536(18), U2-N4 2.2215(18), U2-N5 2.2458(18), U2-N6 2.2241(17), U1-P1 3.0266(5), U1-P2 2.9115(5), U1-C57 2.981(2), U1-C62 2.778(2), U2-P1 3.0358(5), U2-P2 2.9081(5), U2-C57 2.866(2) and U2-C62 2.920(2). complexes of uranium $^{47}$. The U-N bond lengths average $2.251 \AA$, which compares closely to the average $\mathrm{U}-\mathrm{N}$ bond length in 3 .

Variable temperature magnetism. In order to probe the oxidation states of the uranium ions in $\mathbf{3}$ and $\mathbf{4}$ we recorded variable temperature magnetic moment data by means of a superconducting quantum interference device (SQUID) (Supplementary Figures S4-S7). The magnetic data for $\mathbf{3}$ and $\mathbf{4}$ are characteristic of uranium(IV), Fig. 4 (refs 29,48-50). A powdered sample of 3 exhibits a magnetic moment of 3.95 $\mu_{\mathrm{B}}$ at $300 \mathrm{~K}$ and this compares very well with a solution moment of $3.80 \mu_{\mathrm{B}}$ measured in deuterated benzene solution. The magnetic moment of 3 falls to $0.67 \mu_{\mathrm{B}}$ at $1.8 \mathrm{~K}$. For 4 , the magnetic moment at $300 \mathrm{~K}$ for a powdered sample is $3.61 \mu_{\mathrm{B}}$ and this decreases to $0.51 \mu_{\mathrm{B}}$ at $1.8 \mathrm{~K}$. The solution moment of 4 in benzene is $3.90 \mu_{\mathrm{B}}$, which is only slightly higher than the solid state moment. Both sets of magnetometric data for $\mathbf{3}$ and $\mathbf{4}$ clearly tend towards zero magnetic moments at $0 \mathrm{~K}$, which suggests that both complexes contain ${ }^{3} \mathrm{H}_{4}$ uranium(IV) centres, as tetravalent uranium has a singlet magnetic ground state. Interestingly, the magnetic moments of $\mathbf{3}$ and $\mathbf{4}$ are lower than the theoretical magnetic moment for a molecule containing two isolated uranium(IV) centres $\left(5.06 \mu_{\mathrm{B}}\right)$. However, coupling of the uranium centres in $\mathbf{3}$ and $\mathbf{4}$ is not apparent from inspection of the $\chi$ versus $\mathrm{T}$ plots, but resolved magnetic coupling between uranium(IV) centres is very rare ${ }^{49,50}$ and notoriously difficult to detect more generally for uranium, as it is usually masked by other phenomena.

Electronic absorption spectra. We recorded the ultraviolet/visible/near infra-red electronic absorption spectra of 3 and $\mathbf{4}$ over the range $25,000-5,000 \mathrm{~cm}^{-1}$ (Supplementary Figures S8 and S9). The spectra of $\mathbf{3}$ and $\mathbf{4}$ are dominated by intense absorptions in the range $25,000-10,000 \mathrm{~cm}^{-1}$, which most likely originate from charge transfer and $\pi-\pi^{*}$ transitions. At lower energy, weak bands $\left(\varepsilon<100 \mathrm{M}^{-1} \mathrm{~cm}^{-1}\right)$ are apparent, which can be assigned as Laporte forbidden $\mathrm{f} \rightarrow \mathrm{f}$ transitions. These spectra are fully consistent with the presence of uranium(IV) centres $^{51}$ in $\mathbf{3}$ and $\mathbf{4}$,

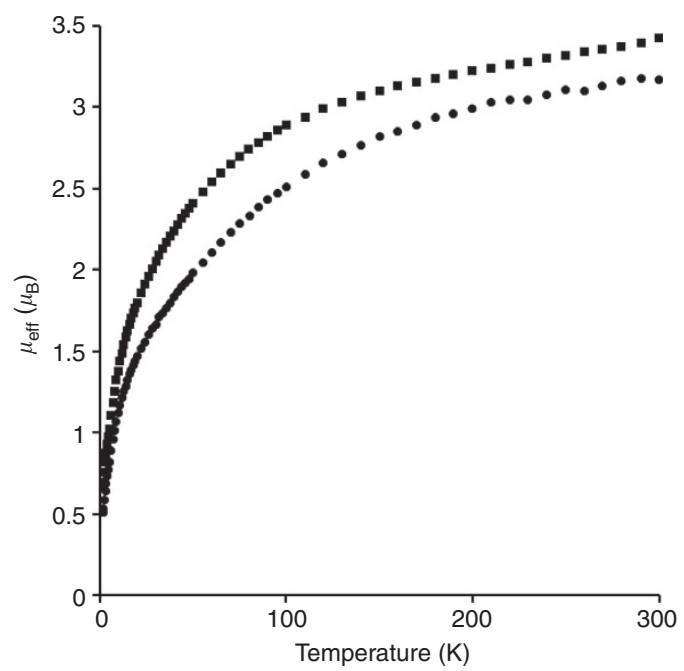

Figure 4 | Variable temperature magnetization data. Data for $\mathbf{3}$ (squares) and $\mathbf{4}$ (circles) recorded on a Quantum Design MPMS XL5 SQUID magnetometer. Data were recorded in an applied dc field of $0.1 \mathrm{~T}$ over the temperature range 1.8-300 K. Diamagnetic corrections of $1195.0 \times 10^{-6}$ $\mathrm{cm}^{3} \mathrm{~mol}^{-1}$ and $887.1 \times 10^{-6} \mathrm{~cm}^{3} \mathrm{~mol}^{-1}$ were applied for $\mathbf{3}$ and $\mathbf{4}$, respectively, using tabulated Pascal constants, and measurements were corrected for the effect of the blank sample holders. 
which is a requirement for charge neutrality with cyclobutadienyl and diphosphacyclobutadienyl dianions.

Density functional theory calculations. In order to probe the electronic structures of $\mathbf{3}$ and $\mathbf{4}$ we carried out unrestricted density functional theory (DFT) calculations on the whole molecule of 3 and on a truncated model of $\mathbf{4}, \mathbf{4 a}$, where the diphosphacyclobutadienyl tert-butyl groups were replaced by methyl groups due to intractable convergence problems encountered with 4 (Supplementary Tables S4-S6). The average calculated and experimental bond lengths for the U$\mathrm{C}_{\text {cyclobutadienyl }}$ and $\mathrm{U}-\mathrm{N}_{\text {amide }}$ interactions in $\mathbf{3}$ are in good agreement $\left(\mathrm{U}-\mathrm{C}_{\text {calc }}=2.793, \mathrm{U}-\mathrm{C}_{\exp }=2.760 \AA\right.$ and $\mathrm{U}-\mathrm{N}_{\text {calc }}=2.281$, $\left.\mathrm{U}-\mathrm{N}_{\text {expt }}=2.257 \AA\right)$. For 4, the average calculated and experimental $\mathrm{U}-\mathrm{N}_{\text {amide }}$ interactions show good agreement (U$\mathrm{N}_{\text {calc }}=2.253, \mathrm{U}-\mathrm{N}_{\text {expt }}=2.234 \AA$ ), whereas the average calculated $\mathrm{U}-\mathrm{C}_{\text {diphosphacyclobutadienyl }}$ and $\mathrm{U}-\mathrm{P}_{\text {diphosphacyclobutadienyl distances }}$ are greater by $c a 0.09$ and $0.08 \AA$, respectively. These differences may be associated with the truncated diphosphacyclobutadienyl unit employed in the calculations for 4a. Nevertheless, given the similarity between the calculated and experimental structures for 3 and $4 \mathbf{a}$, we conclude that the calculations provide qualitative descriptions of the bonding in these molecules. A comparison of calculated data for $\mathbf{3}$ and $\mathbf{4 a}$ is presented in Table 1 and selected $\alpha$-spin Kohn Sham frontier orbitals are illustrated in Fig. 5.

The calculated spin density $(-2.15)$ and charge $(+3.08)$ on uranium and charge on the tetraphenylcyclobutadienyl ring $(-2.36)$ are consistent with a uranium(IV) oxidation state and tetraphenylcyclobutadienyl ${ }^{2-}$ formulation for 3 . The NalewajskiMrozek bond indices for the $\mathrm{U}-\mathrm{C}_{\text {cyclobutadienyl }}$ interactions $(0.22-$ 0.35 , Table 1) and the small overlap populations between atomic orbitals on the bridging ligand and $U$ fragments, (Table 1), suggest that the bonding in $\mathbf{3}$ is dominated by electrostatic contributions with small covalent uranium-cyclobutadienyl contributions. The calculated charges for $4 \mathbf{a}$ (U: +3.39; dimethyldiphosphacyclobutadienyl: -2.76) and spin densities (U: -2.03 ) are consistent with uranium(IV) centres bound to a dimethyldiphosphacyclobutadienyl ${ }^{2-}$ ligand. Again the calculated Nalewajski-Mrozek bond orders for the U-C (0.43) and U-P (0.51) interactions, and the overlap populations (Table 1), underscore the small covalent contributions to the uranium$\mathrm{C}_{2} \mathrm{P}_{2}$ bonding. Noting the dependency of overlap populations with the size of the basis set, we have also performed single-point calculations on $\mathbf{3}$ and $\mathbf{4 a}$ in which we have used a smaller basis set (double zeta basis set (DZ) from the Amsterdam Density Functional suite) for all non-U atoms. These calculations show similar magnitudes for the overlap populations (Supplementary
Table S7) between the $U$ centres and the bridging ligands in 3 and $4 \mathrm{a}$ when compared with the calculations employing the larger double zeta, valence triple zeta, polarized basis set (TZP) basis set
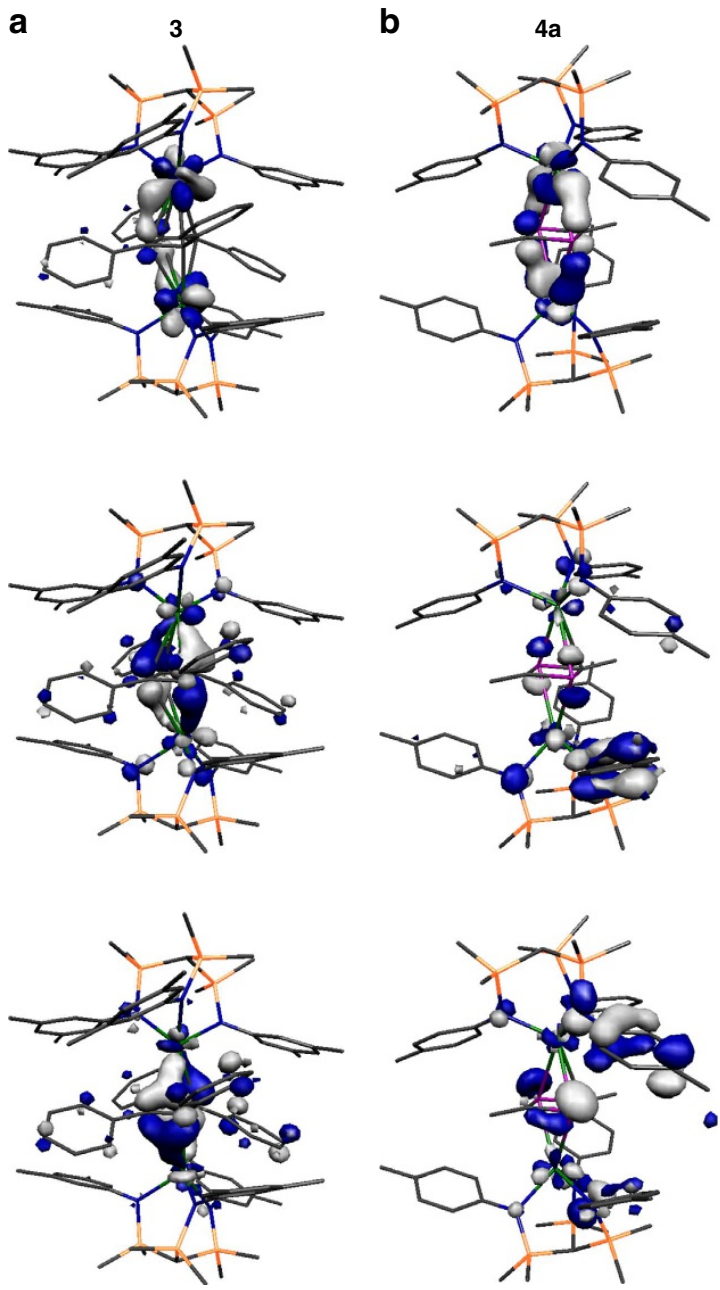

Figure 5 | Selected $\alpha$-spin Kohn Sham frontier molecular orbitals of 3 and 4a. Top to bottom: (a) HOMO-3 (480a, $-3.250 \mathrm{eV}$ ), HOMO-6 (477a, $-4.645 \mathrm{eV}), \mathrm{HOMO}-7(476 \mathrm{a},-4.706 \mathrm{eV})$ of 3; (b) HOMO-3 (392a, $-3.534 \mathrm{eV}$ ), HOMO-6 (389a, $-4.866 \mathrm{eV}), \mathrm{HOMO}-7$ (388a, $-4.941 \mathrm{eV})$ of $\mathbf{4 a}$. These molecular orbitals highlight the principal uranium-bridging ligand interactions in $\mathbf{3}$ and $\mathbf{4 a}$. For the compositions of these molecular orbitals, see Table 1.

\section{Table 1 | Calculated bonding and orbital parameters.}

\begin{tabular}{|c|c|c|c|c|c|c|c|c|c|c|c|}
\hline \multirow[t]{2}{*}{ Complexes } & \multicolumn{2}{|c|}{ Bond indices ${ }^{\star}$} & \multicolumn{3}{|c|}{ Spin densities/charges } & \multicolumn{6}{|c|}{ Composition } \\
\hline & Range & Average & $\mathbf{m}_{\mathbf{u}}^{\dagger}$ & $\mathbf{q u}^{\ddagger}$ & q $_{\text {ring }} \S$ & Orbital & Energy & OPll & Ring\% & $\begin{array}{l}U \text { total }(5 f, 6 d) \\
\%\end{array}$ & $\begin{array}{l}\mathbf{L} \\
\%\end{array}$ \\
\hline 3 & $0.23-0.35$ & 0.29 & -2.15 & +3.08 & -2.36 & $\begin{array}{l}480 a \alpha \\
477 a \alpha \\
476 a \alpha\end{array}$ & $\begin{array}{l}-3.250 \\
-4.645 \\
-4.706\end{array}$ & $\begin{array}{r}0.027 \\
-0.008 \\
0.044\end{array}$ & $\begin{array}{l}23.9 \\
55.7 \\
63.5\end{array}$ & $\begin{array}{l}73.1(67.4,3.9) \\
20.6(15.6,2.8) \\
15.7(12.0,2.4)\end{array}$ & $\begin{array}{l}3.0 \\
23.7 \\
20.9\end{array}$ \\
\hline $4 a$ & $0.40-0.55$ & $\begin{array}{l}0.43(C) \\
0.51(P)\end{array}$ & -2.03 & +3.39 & -2.76 & $\begin{array}{l}392 a \alpha \\
389 a \alpha \\
388 a \alpha\end{array}$ & $\begin{array}{l}-3.534 \\
-4.866 \\
-4.941\end{array}$ & $\begin{array}{l}0.098 \\
0.007 \\
0.038\end{array}$ & $\begin{array}{l}19.5 \\
15.7 \\
12.5\end{array}$ & $\begin{array}{l}75.9(63.9,8.4) \\
22.3(12.9,1.8) \\
17.9(9.5,1.1)\end{array}$ & $\begin{array}{l}4.6 \\
62.0 \\
69.5\end{array}$ \\
\hline
\end{tabular}

Calculated bond indices, spin densities, charges and compositions of the selected $\alpha$-spin frontier orbitals for $\mathbf{3}$ and $\mathbf{4 a}$. 


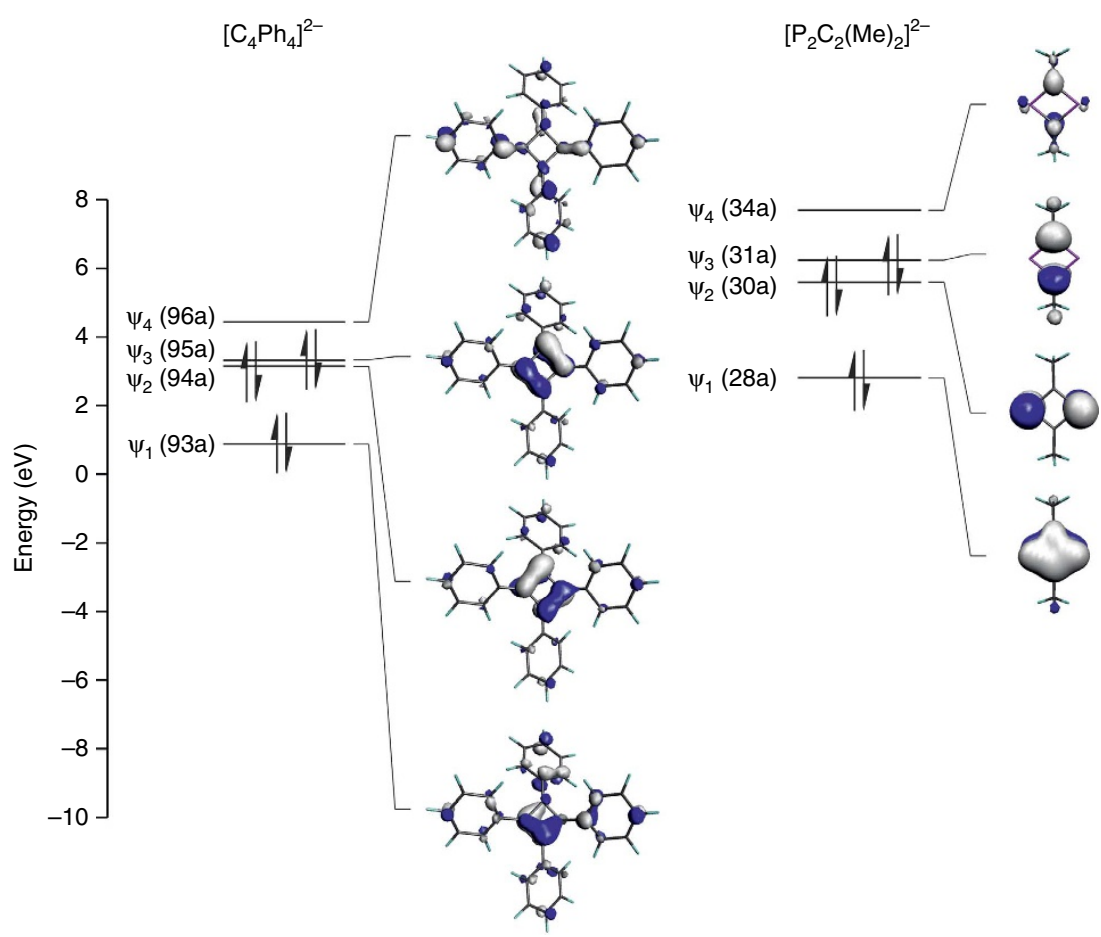

Figure 6 | Frontier orbitals of the cyclobutadienyl and diphosphacyclobutadienyl ligands in $\mathbf{3}$ and $\mathbf{4 a}$. The $\psi_{1-4}$ molecular orbitals of $\left(\mathrm{C}_{4} \mathrm{Ph}_{4}\right)^{2-}$ and $\left(\mathrm{P}_{2} \mathrm{C}_{2} \mathrm{Me}_{2}\right)^{2-}$ were calculated by DFT at the geometries for these fragments determined by geometry optimizations for the molecules $\mathbf{3}$ and $\mathbf{4 a}$.

for all atoms (Table 1). Thus, a similar description of the bonding in $\mathbf{3}$ and $\mathbf{4 a}$ emerges for calculations employing a smaller basis set.

For 3, the three highest occupied $\alpha$-spin molecular orbitals (HOMOs) are almost entirely of uranium non-bonding $5 \mathrm{f}$ character. HOMO-3 (480a) reveals a modest $\delta$-type combination between the empty $\psi_{4}$ orbital of the cyclobutadienyl ligand (Fig. 6) and mainly the 5f-orbitals of the uranium centres (Table 1). HOMO-6 (477a) and HOMO-7 (476a) involve uranium-cyclobutadienyl combinations that are of $\pi$-character and employ $\psi_{3}$ and $\psi_{2}$ cyclobutadienyl $\pi$-orbital combinations (Fig. 6), respectively, which are usually invoked in the molecular orbital descriptions of the bonding between transition metal centres and cyclobutadienyl $^{5}$. However, for 3 , the notable difference is that the uranium $5 \mathrm{f}$-orbitals are almost exclusively employed, whereas transition metals typically employ $\mathrm{p}$ - and d-orbital combinations. DFT calculations on 4 a reveal a similar manifold as for $\mathbf{3}$. The top three HOMOs of $\mathbf{4 a}$ are predominantly uranium $5 f$ character. HOMO-3 (392a) exhibits a $\delta$-type combination involving the empty $\psi_{4}$ orbital of the diphosphacyclobutadienyl ligand, and $\pi$-type combinations involving the $\psi_{2}$ and $\psi_{3} \pi$-orbitals (Fig. 6) are found for HOMO-7 (388a) and HOMO-6 (389a), respectively.

The orbital overlap populations (Table 1) indicate that HOMO-3, HOMO-6 and HOMO-7 in $\mathbf{3}$ and $\mathbf{4 a}$ make little contribution to the bonding between the bridging ring and $\mathrm{U}$ fragments. This similarity in magnitude of the overlap populations for the $\delta$ - and $\pi$-type interactions in $\mathbf{3}$ and $\mathbf{4 a}$ contrasts to the situation found in uranium-inverted sandwich complexes of arenes $^{25-36}$ and the cyclo-octatetraenide dianion, where $\delta$ bonding has been shown computationally to dominate for these larger aromatic systems ${ }^{26}$. Germane to this point, it has been noted that $\delta$-bonding in transition metal metallocene complexes is generally weaker than in transition metal arene complexes; this is usually justified on the basis of size-matching between the metal and ligand frontier orbitals ${ }^{4}$. For 3 and $4 a$, the small overlap populations for HOMO-3, HOMO-6 and HOMO-7 may result from the relatively small size of the four-membered cyclobutadienyl and diphosphacyclobutadienyl rings, which limits the involvement of the $\psi_{4}, \psi_{3}$ and $\psi_{2}$ orbitals in the bonding between these rings and uranium. The highly angular requirement of the bonding may also account for the dominance of 5f-orbital participation in the uranium-bridging ligand interactions in $\mathbf{3}$ and $\mathbf{4 a}$ (Table 1), as well as small ligand centres such as in UE double and triple bonds $(\mathrm{E}=\mathrm{C}, \mathrm{N}, \mathrm{O})^{12,14-17,52-54}$. In contrast, more significant uranium $6 \mathrm{~d}$-orbital participation is invoked in the molecular orbital treatment of uranocene with the larger cyclo-octatetraenide ligand ${ }^{55,56}$; here it may be that the more diffuse, less angular 6d-orbitals are better suited to bonding to spatially larger ligands.

\section{Discussion}

We have shown that employing highly reducing, high-valent diuranium $(\mathrm{V})$ inverted arene complexes provides effective synthetic tools for preparing the first f-block cyclobutadienyl (3) and diphosphacyclobutadienyl (4) complexes. Compounds 3 and 4 are prepared by formal [2+2]-cycloaddition reactions accompanied by extrusion of toluene. For the least polar diphenylacetylene, the cycloaddition is slow, but the energetic stabilization afforded from aromaticity following cyclization eventually overcomes the inherent strain in constructing a fourmembered ring, and it seems likely that two uranium centres acting cooperatively are required to effect this transformation. For the more polar phospha-alkyne, the cycloaddition is rapid. The bonding in $\mathbf{3}$ and $\mathbf{4}$ can be described as principally electrostatic, but modest $\delta$ - and $\pi$-type orbital combinations may be identified for each. The limited extent of these interactions is consistent with the relatively small size of the four-membered cyclobutadienyl and diphosphacyclobutadienyl rings. These results further our understanding of 5f-orbital bonding theory and may have applicability in designing new synthetic methodologies for the construction of novel functional group architectures. 


\section{Methods}

General. Experiments were carried out under a dry, oxygen-free dinitrogen atmosphere using Schlenk-line and glove-box techniques. All solvents and reagents were rigorously dried and deoxygenated before use. All compounds were characterized by elemental analyses, NMR, fourier transform infra-red (FTIR) and ultraviolet/visible/near infra-red (NIR) electronic absorption spectroscopies, Evans and SQUID magnetometric methods, and single-crystal X-ray diffraction studies.

Preparation of $\left[\left\{\mathbf{U}\left(\mathbf{T s}^{\mathbf{X y}}\right)\right\}_{\mathbf{2}}\left(\boldsymbol{\mu}: \eta^{\mathbf{5}} \boldsymbol{\eta}^{\mathbf{5}}-\mathbf{C}_{\mathbf{4}} \mathbf{P h} \mathbf{4}\right)\right]$ (3). Toluene (15 ml) was added to a cold $\left(-78^{\circ} \mathrm{C}\right)$ stirring mixture of $\mathbf{1}(0.83 \mathrm{~g}, 0.50 \mathrm{mmol})$ and diphenylacetylene $(0.36 \mathrm{~g}, 2.00 \mathrm{mmol})$. The mixture was allowed to warm to room temperature with stirring over $16 \mathrm{~h}$. All volatiles were removed in vacuo to give a brown solid. The solid was extracted into hexanes and stored at room temperature for 43 days to give crystals of 3.0.5 (PhCCPh). $0.5\left(\mathrm{C}_{6} \mathrm{H}_{14}\right)$ as brown blocks. Yield: $0.20 \mathrm{~g}, 20 \%$. Anal. Cald. for $\mathrm{C}_{97} \mathrm{H}_{117} \mathrm{~N}_{6} \mathrm{Si}_{6} \mathrm{U}_{2}$ : C, 58.46; H, 6.08; N, 4.09\%. Found: C, 58.48; H, 6.04; N, $3.71 \% .{ }^{1} \mathrm{H}$ NMR $\left(\mathrm{C}_{6} \mathrm{D}_{6}\right): \delta 11.81(2 \mathrm{H}, \mathrm{m}, \mathrm{p}$ - $\mathrm{CH}$-phenyl), $8.00(4 \mathrm{H}, \mathrm{m}, \mathrm{CH}$-phenyl), $7.63(2 \mathrm{H}, \mathrm{m}, \mathrm{CH}$-diphenylacetylene), 7.45 ( $3 \mathrm{H}, \mathrm{m}, \mathrm{CH}$-diphenylacetylene), 6.52 (4H, br s, CH-phenyl), 6.36 (4H, br s, $\mathrm{CH}$-phenyl), 4.14 (4H, s, $\mathrm{CH}$-phenyl), 3.57 $\left(2 \mathrm{H}, \mathrm{s}, \mathrm{p}-\mathrm{CH}\right.$-phenyl), $1.94\left(6 \mathrm{H}\right.$, br s, p-CH) $0.13\left(36 \mathrm{H}, \mathrm{s}, \mathrm{CH}_{3}\right),-0.35(36 \mathrm{H}, \mathrm{s}$, $\left.\mathrm{CH}_{3}\right),-4.21(12 \mathrm{H}, \mathrm{s}, \mathrm{o}-\mathrm{CH}),-41.95(2 \mathrm{H}, \mathrm{s}, \mathrm{Si}-\mathrm{CH})$. Magnetic moment (Evans method, $\mathrm{C}_{6} \mathrm{D}_{6}, 298 \mathrm{~K}$ ): $\mu_{\text {eff }}=3.80 \mu_{\mathrm{B}}$. FTIR $v \mathrm{~cm}^{-1}$ (Nujol): 3022 (sh, s), $2280(\mathrm{~m})$, 1596 (vs), 1584 (vs), 1488 (s), 1330 (m), 1298 (br, s), 1253 (vs), 1157 (br, vs), 1094 (vbr, m), 1030 (vbr, vs), 975 (m), 888 (s), 846 (br, vs), 816 (br, vs), 754 (m), 722 (w), $700(\mathrm{~m}), 693(\mathrm{~m}), 672(\mathrm{w}), 652(\mathrm{~m}), 565(\mathrm{w}), 538(\mathrm{w}), 497(\mathrm{~m})$.

\section{Preparation of $\left[\left\{\mathrm{U}\left(\mathbf{T s}^{\mathrm{Tol}}\right)\right\}_{2}\left(\mu: \eta^{\mathbf{4}} \eta^{\mathbf{4}}-\mathrm{C}_{2} \mathrm{P}_{2} \mathrm{Bu}^{\mathrm{t}} \mathbf{2}\right)\right]$ (4). A solution of $\mathrm{Bu}{ }^{\mathrm{t}} \mathrm{C} \equiv \mathrm{P}$} $\mathrm{O}\left(\mathrm{SiMe}_{3}\right)_{2}(0.26 \mathrm{~g}, 1.00 \mathrm{mmol})$ in toluene $(5 \mathrm{ml})$ was added slowly to a solution of 2 $(0.79 \mathrm{~g}, 0.50 \mathrm{mmol})$ in toluene $(10 \mathrm{ml})$ at $-78^{\circ} \mathrm{C}$. The resultant mixture was allowed to warm to room temperature with stirring over $16 \mathrm{~h}$. Volatiles were removed in vacuo and the solids were washed with hexanes $(1 \times 2 \mathrm{ml})$ then dried in vacuo to yield analytically pure 4 as a pyrophoric brown powder. Yield: $0.58 \mathrm{~g}$, $69 \%$. Red tablet-shaped crystals of $\mathbf{4}$ were grown from a saturated solution of $\mathbf{4}$ in toluene stored at $-30{ }^{\circ} \mathrm{C}$ for $16 \mathrm{~h}$. Anal. Cald. for $\mathrm{C}_{66} \mathrm{H}_{98} \mathrm{~N}_{6} \mathrm{P}_{2} \mathrm{Si}_{6} \mathrm{U}_{2}: \mathrm{C}, 47.13 ; \mathrm{H}$, 5.87; N, 5.00\%. Found: C, 46.86; H, 5.52; N, 4.93\%. ${ }^{1} \mathrm{H}$ NMR $\left(\mathrm{C}_{6} \mathrm{D}_{6}\right): \delta 23.37(18 \mathrm{H}$, s, $\left.\mathrm{Bu}^{\mathrm{t}}\right), 9.00(12 \mathrm{H}, \mathrm{s}, \mathrm{Ar}-\mathrm{CH}), 8.81(12 \mathrm{H}, \mathrm{s}, \mathrm{Ar}-\mathrm{CH}), 3.80\left(18 \mathrm{H}, \mathrm{s}, \mathrm{Ar}-\mathrm{CH}_{3}\right),-4.70$ $\left(36 \mathrm{H}, \mathrm{s}, \mathrm{Si}-\mathrm{CH}_{3}\right),-69.78(2 \mathrm{H}, \mathrm{s}, \mathrm{Si}-\mathrm{CH}) .{ }^{31} \mathrm{P}\left\{{ }^{1} \mathrm{H}\right\}$ NMR $\left(\mathrm{C}_{6} \mathrm{D}_{6}\right): \delta 535.52\left(\mathrm{C}_{2} P_{2}\right)$. Magnetic moment (Evans method, $\left.\mathrm{C}_{6} \mathrm{D}_{6}, 298 \mathrm{~K}\right): \mu_{\mathrm{eff}}=3.90 \mu_{\mathrm{B}}$. FTIR $v / \mathrm{cm}^{-1}$ (Nujol): 1606 (w), 1514 (m), 1498 (vs), 1366 (s), 1300 (w), 1286 (m), 1253 (s), 1243 (s), $1211(\mathrm{~s}), 1172(\mathrm{w}), 1104(\mathrm{w}), 1015$ (br, w), $974(\mathrm{~m}), 932(\mathrm{~m}), 896(\mathrm{~m}), 839$ (vs), 809 (s), $764(\mathrm{~m}), 724(\mathrm{w}), 710(\mathrm{~m}), 700(\mathrm{w}), 544(\mathrm{w}), 503(\mathrm{~m})$

DFT calculations. Unrestricted geometry optimizations were performed for the full model of $\mathbf{3}$ using coordinates derived from the X-ray crystal structure. Attempts to optimize the full structure of $\mathbf{4}$ resulted in intractable convergence problems in geometry optimization. Thus, we pruned the diphosphacyclobutadienyl tert-butyl groups to methyl groups in the truncated model $4 \mathbf{a}$. No constraints were imposed on the structures during the geometry optimizations. The calculations were performed using the Amsterdam Density Functional suite version 2010.01 (refs 57,58). The overlap populations and orbital compositions were analysed by AOMix ${ }^{59,60}$. Further details are available in the Supplementary Methods.

\section{References}

1. Kealy, T. J. \& Pauson, P. L. A new type of organo-iron compound. Nature 168, 1039-1040 (1951)

2. Miller, S. A., Tebboth, J. A. \& Tremaine, J. F. Dicyclopentadienyliron. J. Chem. Soc. 632-635 (1952)

3. Werner, H. At least 60 years of ferrocene: the discovery and rediscovery of the sandwich complexes. Angew. Chem. Int. Ed. 51, 6052-6058 (2012)

4. Elschenbroich, C. Organometallics. 3rd edn (Wiley-VCH, Weinheim, Germany, 2005).

5. Seyferth, D. (Cyclobutadiene)iron tricarbonyl - a case of theory before experiment. Organometallics 22, 2-20 (2003).

6. Astruc, D. Modern arene chemistry (Wiley VCH, Weinheim, Germany, 2002).

7. Efraty, A. Cyclobutadienemetal complexes. Chem. Rev. 77, 691-744 (1977).

8. Donaldson, W. A. Comprehensive Organometallic Chemistry II. (eds Abel, E. W., Stone, F. G. A. \& Wilkinson, G.) (Pergamon, Oxford, UK, 1995; 12 Chapter 6.2, pp 623).

9. Arndt, S. \& Okuda, J. Mono(cyclopentadienyl) complexes of the rare-earth metals. Chem. Rev. 102, 1953-1976 (2002).

10. Evans, W. J. \& Davis, B. L. Chemistry of tris(pentamethylcyclopentadienyl) f-element complexes, $\left(\mathrm{C}_{5} \mathrm{Me}_{5}\right)_{3} \mathrm{M}$. Chem. Rev. 102, 2119-2025 (2002).

11. Bochkarev, M. N. Synthesis, arrangement, and reactivity of arene-lanthanide compounds. Chem. Rev. 102, 2089-2118 (2002).

12. Ephritikhine, M. The vitality of uranium molecular chemistry at the dawn of the XXIst century. Dalton Trans. 2501-2516 (2006).

13. Fox, A. R., Bart, S. C., Meyer, K. \& Cummins, C. C. Towards uranium catalysts. Nature 455, 341-349 (2008)
14. Hayton, T. W. Metal-ligand multiple bonding in uranium: structure and reactivity. Dalton Trans. 39, 1145-1158 (2010).

15. King, D. M. et al. Synthesis and structure of a terminal uranium nitride complex. Science 337, 717-720 (2012).

16. La Pierre, H. S. \& Meyer, K. Uranium-ligand multiple bonding in uranyl analogues, $[\mathrm{L}=\mathrm{U}=\mathrm{L}]^{\mathrm{n}}+$, and the inverse trans influence. Inorg. Chem. 52, 529-539 (2013).

17. Hayton, T. W. Recent developments in actinide-ligand multiple bonding. Chem. Commun. 49, 2956-2973 (2013)

18. Reynolds, L. T. \& Wilkinson, G. $\pi$-cyclopentadienyl compounds of uranium-IV and thorium-IV. J. Inorg. Nucl. Chem. 2, 246-253 (1956).

19. Wong, C.-H., Yen, T.-M. \& Lee, T.-Y. The crystal structure of uranium chloride $\pi$-tricyclopentadienyl. Acta Cryst. 18, 340-345 (1965).

20. Streitwieser, Jnr A. \& Müller-Westerhoff, U. Bis(cyclooctatetraenyl)uranium (uranocene). A new class of sandwich complexes that utilize atomic f orbitals. J. Am. Chem. Soc. 90, 7364-7364 (1968).

21. Zalkin, A. \& Raymond, K. N. The structure of di- $\pi$-cyclooctatetraeneuranium (uranocene). J. Am. Chem. Soc. 91, 5667-5668 (1969).

22. Arliguie, T., Lance, M., Nierlich, M., Vigner, J. \& Ephritikhine, E. Inverse cycloheptatrienyl sandwich complexes. Crystal structure of $\left[\mathrm{U}\left(\mathrm{BH}_{4}\right)_{2}\left(\mathrm{OC}_{4} \mathrm{H}_{8}\right)_{5}\right]\left[\left(\mathrm{BH}_{4}\right)_{3} \mathrm{U}\left(\mu-\eta^{7}: \eta^{7}-\mathrm{C}_{7} \mathrm{H}_{7}\right) \mathrm{U}\left(\mathrm{BH}_{4}\right)_{3}\right]$. J. Chem. Soc. Chem Commun. 847-848 (1994).

23. Arliguie, T., Lance, M., Nierlich, M., Vigner, J. \& Ephritikhine, E. Synthesis and

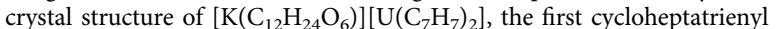
sandwich compound. J. Chem. Soc. Chem. Commun. 183-184 (1995).

24. Cesari, M., Pedretti, U., Zazetta, A., Lugli, G. \& Marconi, W. Synthesis and structure of a $\pi$-Arene complex of uranium(III) - aluminium chloride. Inorg Chim. Acta 5, 439-444 (1971).

25. Diaconescu, P. L., Arnold, P. L., Baker, T. A., Mindiola, D. J. \& Cummins, C. C. Arene-bridged diuranium complexes: inverted sandwiches supported by $\delta$ backbonding. J. Am. Chem. Soc. 122, 6108-6109 (2000).

26. Diaconescu, P. L. \& Cummins, C. C. Diuranium inverted sandwiches involving naphthalene and cyclooctatetraene. J. Am. Chem. Soc. 124, 7660-7661 (2002).

27. Evans, W. J., Kozimor, S. A., Ziller, J. W. \& Kaltsoyannis, N. Structure, reactivity, and density functional theory analysis of the six-electron reductant, $\left[\left(\mathrm{C}_{5} \mathrm{Me}_{5}\right)_{2} \mathrm{U}\right]_{2}\left(\mu-\eta^{6}: \eta^{6}-\mathrm{C}_{6} \mathrm{H}_{6}\right)$, synthesized via a new mode of $\left(\mathrm{C}_{5} \mathrm{Me}_{5}\right)_{3} \mathrm{M}$ reactivity. J. Am. Chem. Soc. 126, 14533-14547 (2004).

28. Evans, W. J., Traina, C. A. \& Ziller, J. W. Synthesis of heteroleptic uranium $\left(\mu-\eta^{6}: \eta^{6}-\mathrm{C}_{6} \mathrm{H}_{6}\right)^{2-}$ sandwich complexes via facile displacement of $\left(\mathrm{C}_{5} \mathrm{Me}_{5}\right)^{1-}$ by ligands of lower hapticity and their conversion to heteroleptic bis(imido) compounds. J. Am. Chem. Soc. 131, 17473-17481 (2009).

29. Mills, D. P. et al. A delocalized arene-bridged diuranium single-molecule magnet. Nat. Chem. 3, 454-460 (2011)

30. Monreal, M. J., Khan, S. I., Kiplinger, J. L. \& Diaconescu, P. L. Molecular quadrangle formation from a diuranium $\mu-\eta^{6}: \eta^{6}$-toluene complex. Chem. Commun. 47, 9119-9121 (2011).

31. Patel, D., Moro, F., McMaster, J., Lewis, W., Blake, A. J. \& Liddle, S. T. A forma high oxidation state inverse-sandwich diuranium complex: a new route to f-block-metal bonds. Angew. Chem. Int. Ed. 50, 10388-10392 (2011).

32. Diaconescu, P. L. \& Cummins, C. C. $\mu-\eta^{6}: \eta^{6}$-Arene-bridged diuranium hexakisketimide complexes isolable in two states of charge. Inorg. Chem. 51, 2902-2916 (2012).

33. Arnold, P. L., Mansell, S. M., Maron, L. \& McKay, D. Spontaneous reduction and $\mathrm{C}-\mathrm{H}$ borylation of arenes mediated by uranium(III) disproportionation. Nat. Chem. 4, 668-674 (2012).

34. Mougel, V. et al. Siloxides as supporting ligands in uranium(III)-mediated small-molecule activation. Angew. Chem. Int. Ed. 51, 12280-12284 (2012).

35. Patel, D. et al. A triamido-uranium(V) inverse-sandwich $10 \pi$-toluene tetraanion arene complex. Dalton Trans. 42, 5224-5227 (2013).

36. Vlaisavljevich, B., Diaconescu, P. L., Lukens, Jr W. L., Gagliardi, L. \& Cummins, C. C. Investigations of the electronic structure of arene-bridged diuranium complexes. Organometallics 32, 1341-1352 (2013).

37. Haskel, A., Straub, T., Dash, A. K. \& Eisen, M. S. Oligomerization and crossoligomerization of terminal alkynes catalyzed by organoactinide complexes. J. Am. Chem. Soc. 121, 3014-3024 (1999).

38. Haskel, A., Wang, J. Q., Straub, T., Neyroud, T. G. \& Eisen, M. S. Controlling the catalytic oligomerization of terminal alkynes promoted by organoactinides: a strategy to short oligoners. J. Am. Chem. Soc. 121, 3025-3034 (1999).

39. Wang, J. Q., Dash, A. K., Berthet, J.-C., Ephritikhine, M. \& Eisen, M. S Selective dimerization of terminal alkynes promoted by the cationic actinide compound $\left[\left(\mathrm{Et}_{2} \mathrm{~N}\right)_{3} \mathrm{U}\right]\left[\mathrm{BPh}_{4}\right]$. Formation of the alkyne $\pi$-complex $\left[\left(\mathrm{Et}_{2} \mathrm{~N}\right)_{2} \mathrm{U}\left(\mathrm{C} \equiv \mathrm{C}^{t} \mathrm{Bu}\right)\left(\eta^{2}-\mathrm{HC} \equiv \mathrm{C}^{t} \mathrm{Bu}\right)\right]\left[\mathrm{BPh}_{4}\right]$. Organometallics 18, 2407-2409 (1999).

40. Wang, J., Kapon, M., Berthet, J.-C., Ephritikhine, M. \& Eisen, M. S. Cross dimerization of terminal alkynes catalyzed by $\left[\left(\mathrm{Et}_{2} \mathrm{~N}\right)_{3} \mathrm{U}\right]\left[\mathrm{BPh}_{4}\right]$. Inorg. Chim. Acta 334, 183-192 (2002).

41. Kosog, B., Kefalidis, C. E., Heinemann, F. W., Maron, L. \& Meyer, K. Uranium(III)-mediated C-C-coupling of terminal alkynes: formation of 
dinuclear uranium(IV) vinyl complexes. J. Am. Chem. Soc. 134, 12792-12797 (2012).

42. Bertrand, G., Tortech, L., Fichou, D., Malacria, M., Aubert, C. \& Gandon, V. An improved protocol for the synthesis of $\left[\left(\eta^{4}-\mathrm{C}_{4} \mathrm{R}_{4}\right) \mathrm{Co}\left(\eta^{5}-\mathrm{C}_{5} \mathrm{H}_{5}\right)\right]$ complexes. Organometallics 31, 126-132 (2012).

43. Cambridge Structural Database. CSD version 1.11, accessed 08/03/2013, http://cds.dl.ac.uk/cds/datasets/crys/csd/csd.html.

44. Berthet, J. C. \& Ephritikhine, M. New advances in the chemistry of uranium amide compounds. Coord. Chem. Rev. 178-180, 83-116 (1998).

45. Frey, A. S. P., Cloke, F. G. N., Hitchcock, P. B. \& Green, J. C. Activation of $\mathrm{P}_{4}$ by $\mathrm{U}\left(\eta^{5}-\mathrm{C}_{5} \mathrm{Me}_{5}\right)\left(\eta^{8}-\mathrm{C}_{8} \mathrm{H}_{6}\left(\mathrm{Si}^{\mathrm{i}} \mathrm{Pr}_{3}\right)_{2}-1,4\right)(\mathrm{THF})$; the X-ray structure of $\left[\mathrm{U}\left(\eta^{5}-\right.\right.$ $\left.\left.\mathrm{C}_{5} \mathrm{Me}_{5}\right)\left(\eta^{8}-\mathrm{C}_{8} \mathrm{H}_{6}\left(\mathrm{Si}^{\mathrm{i}} \mathrm{Pr}_{3}\right)_{2}-1,4\right)\right]_{2}\left(\mu-\eta^{2}: \eta^{2}-\mathrm{P}_{4}\right)$. N. J. Chem. 35, 2022-2026 (2011).

46. Stephens, F. H. PhD Thesis, Massachusetts Institute of Technology (2004).

47. Baudry, D., Ephritikhine, M., Nief, F., Ricard, L. \& Mathey, F. Synthesis of phospholyltetrahydroboratouranium complexes. Crystal Structure of $\left[\left(\eta^{5}-\right.\right.$ $\left.\mathrm{C}_{4} \mathrm{Me}_{4} \mathrm{P}\right)_{2} \mathrm{U}\left(\mathrm{BH}_{4}\right)_{2}$ ]. Angew. Chem. Int. Ed. 29, 1485-1486 (1990).

48. Castro-Rodríguez, I. \& Meyer, K. Small molecule activation at uranium coordination complexes: control of reactivity via molecular architecture. Chem. Commun. 1353-1368 (2006).

49. Lam, O. P., Heinemann, F. W. \& Meyer, K. Activation of elemental S, Se and Te with uranium(III): bridging U-E-U $(\mathrm{E}=\mathrm{S}, \mathrm{Se})$ and diamond-core complexes $\mathrm{U}-(\mathrm{E})_{2}-\mathrm{U}(\mathrm{E}=\mathrm{O}, \mathrm{S}, \mathrm{Se}, \mathrm{Te})$. Chem. Sci. 2, 1538-1547 (2011).

50. Gardner, B. M. et al. Homologation and functionalization of carbon monoxide by a recyclable uranium complex. Proc. Natl Acad. Sci. USA 109, 9265-9270 (2012).

51. Morris, D. E., Da Re, R. E., Jantunen, K. C., Castro-Rodriguez, I. \& Kiplinger, J. L. Trends in electronic structure and redox energetics for early-actinide pentamethylcyclopentadienyl complexes. Organometallics 23, 5142-5153 (2004).

52. Cooper, O. J. et al. Uranium-Carbon Multiple Bonding: Facile Access to the Pentavalent Uranium Carbene $\left[\mathrm{U}\left\{\mathrm{C}\left(\mathrm{PPh}_{2} \mathrm{NSiMe}_{3}\right)_{2}\right\}(\mathrm{Cl})_{2}(\mathrm{I})\right]$ and Comparison of $\mathrm{U}^{\mathrm{V}}=\mathrm{C}$ and $\mathrm{U}^{\mathrm{IV}}=\mathrm{C}$ Double Bonds. Angew. Chem. Int. Ed. 50, 2383-2386 (2011).

53. Mills, D. P. et al. Synthesis of a uranium(VI)-carbene: reductive formation of uranyl $(\mathrm{V})$-methanides, oxidative preparation of a $\left[\mathrm{R}_{2} \mathrm{C}=\mathrm{U}=\mathrm{O}\right]^{2+}$ analogue of the $[\mathrm{O}=\mathrm{U}=\mathrm{O}]^{2+}$ uranyl ion $\left(\mathrm{R}=\mathrm{Ph}_{2} \mathrm{PNSiMe}_{3}\right)$, and comparison of the nature of $\mathrm{U}^{\mathrm{IV}}=\mathrm{C}, \mathrm{U}^{\mathrm{V}}=\mathrm{C}$, and $\mathrm{U}^{\mathrm{VI}}=\mathrm{C}$ double bonds. J. Am. Chem. Soc. 134, 10047-10054 (2012).

54. King, D. M. et al. Isolation and characterization of a uranium(VI)-nitride triple bond. Nat. Chem. 5, 482-488 (2013)

55. Streitwieser, Jnr A. et al. Preparation and properties of uranocene, di- $\pi$ cyclooctatetraeneuranium(IV). J. Am. Chem. Soc. 95, 8644-8649 (1973).
56. Seyferth, D. Uranocene. The first member of a new class of organometallic derivatives of the f elements. Organometallics 23, 3562-3583 (2004).

57. Fonseca-Guerra, C., Snijders, J. G., Velde, G. \& te, Baerends, E. J. Towards an order-N DFT method. Theor. Chem. Acc. 99, 391-403 (1998).

58. Velde, G. et al. Chemistry with ADF. J. Comput. Chem. 22, 931-967 (2001).

59. Gorelsky, S. I. AOMix: Program for Molecular Orbital Analysis; version 6.8 (University of Ottawa, 2013) http://www.sg-chem.net/.

60. Gorelsky, S. I. \& Lever, A. B. P. Electronic structure and spectra of ruthenium diimine complexes by density functional theory and INDO/S. Comparison of the two methods. J. Organomet. Chem 635, 187-196 (2001).

\section{Acknowledgements}

We are grateful to the European Research Council, the UK Engineering and Physical Sciences Research Council, the University of Nottingham and the UK National Nuclear Laboratory for generous funding and support, and the Royal Society for the award of a University Research Fellowship (S.T.L.).

\section{Author contributions}

D.P. synthesized and characterized the compounds. J.M. carried out and analysed the DFT calculations. W.L. and A.J.B. carried out the X-ray single-crystal structure analyses. S.T.L. originated the central idea, supervised the work, analysed the data and wrote the manuscript with contributions from all the co-authors.

\section{Additional information}

Accession codes: The X-ray crystallographic coordinates for structures reported in this Article have been deposited at the Cambridge Crystallographic Data Centre (CCDC), under deposition number CCDC 929447 (3) and 929448 (4). These data can be obtained free of charge from The Cambridge Crystallographic Data Centre via www.ccdc.cam. ac.uk/data_request/cif.

Supplementary Information accompanies this paper at http://www.nature.com/ naturecommunications

Competing financial interests: The authors declare no competing financial interests.

Reprints and permission information is available online at http://npg.nature.com/ reprintsandpermissions/

How to cite this article: Patel, D. et al. Reductive assembly of cyclobutadienyl and diphosphacyclobutadienyl rings at uranium. Nat. Commun. 4:2323 doi: $10.1038 /$ ncomms3323 (2013). 